\title{
Thermoregulation in babies immediately after birth
}

\author{
O. R. C. SMALES AND R. KIME \\ From the Department of Child Health, University Hospital and Medical School, Nottingham, and \\ City Hospital, Nottingham
}

SUMmARY The fall in body temperature that occurs in babies soon after birth is influenced by the baby's weight and its environmental conditions. The rate of oxygen consumption $1 \frac{1}{2}$ hours after birth was unrelated to body temperature and was only slightly raised, indicating a limited thermogenic capacity. A radiant heater effectively prevented cooling in babies kept with their mothers in the delivery room. Washing soon after birth caused a significant cooling. Healthy term babies were found to have a limited thermogenic response to a cool environment over the first 12 hours of life and efforts to limit heat losses should be concentrated on this period.

Under normal delivery room conditions the newborn baby's body temperature falls rapidly unless efforts are made to prevent cooling. The baby's large surface area in relation to volume, high thermal conductance, and wet surface result in unusually large heat losses. In normal term babies, a metabolic response to cooling is reported to occur within minutes of birth but is insufficient to maintain body temperature until the second or third day of life (Brück, 1961; Hey and Katz, 1969). Both hypoxia and hypercapnia can limit this response and these may be relevant factors in the period immediately after birth (Stupfel, 1959; Scopes and Ahmed, 1966).

Although most obstetric units have a clear procedure for managing the newborn baby, there is no generally accepted policy for minimising heat loss. Washing the baby soon after birth is likely to lead to further heat loss, but it is often considered desirable on social grounds. By measuring the rate of oxygen consumption and body temperature, we have studied both the effects of washing the baby and the value of using a radiant heater during the first $1 \frac{1}{2}$ hours of life and have found, contrary to previous reports, that infants have a limited capacity to produce extra heat over the first few hours of life.

\section{Patients and methods}

Forty normal term babies delivered vaginally without complications were studied $1 \frac{1}{2}$ hours after birth. In 19 no sedation had been given to the mother within 2 hours of delivery and in the remainder

Received 5 August 1976 pethidine or pethidine and promethazine had been used. The condition of every baby was good at birth (Apgar score 8 or more at 3 minutes) and after aspiration of the oropharynx the baby was dried and placed well wrapped in a cot in the mother's delivery room at an air temperature of $24 \cdot 1^{\circ} \mathrm{C} \pm 0 \cdot 2$ (SEM). Half the babies were provided with additional warmth from a radiant heater (Vickers). This is a fixed output 400 watt radiant heater positioned $0.8 \mathrm{~m}$ above the cot surface. The babies were dressed in a nappy and nightshirt and swaddled with two blankets while under the heater. At about 50 minutes after birth half the babies were also subjected to the 'primary toilet' procedure in which the naked baby is cleaned with warm swabs. The procedure took between 10 and 20 minutes.

The 40 babies included in this part of the study were therefore studied sequentially in 4 groups: group 1 were washed and not kept under a radiant heater; group 2 were not washed and not kept under a radiant heater; group 3 were washed and kept under a heater; group 4 were not washed and kept under a heater.

At $1 \frac{1}{2}$ hours of age the baby's rate of $\mathrm{O}_{2}$ consumption was measured using an open circuit system designed for use in the neonatal nursery (Smales, 1978). A mask applied to the baby's face for collection of the mixed expired gases caused only brief restlessness and it was possible to make all measurements during sleep or quiet wakefulness. A stable record of the oxygen content of mixed expired gas could be obtained within 10-20 minutes. After this procedure the baby's rectal temperature was recorded using a standard mercury thermometer inserted $3 \mathrm{~cm}$ into the rectum. 
In the second part of the study the rate of $\mathrm{O}_{2}$ consumption was measured in 32 normal term babies after 20 minutes in a cool environment. All the babies were normal vaginal deliveries and were tested only once, at different ages and at a variable time in relation to their feeds. The temperature of the cool environment was $6^{\circ} \mathrm{C}$ below the lower limit of the thermoneutral zone as determined from Hey's chart (Hey, 1971). This environment was produced by modifying the incubator temperature to allow for radiant heat loss (Hey and Mount, 1967). After 20 minutes the baby's rate of $\mathrm{O}_{2}$ consumption and rectal temperature were measured. Maternal consent to the investigation was obtained in every case.

\section{Results}

Management in first $1 \frac{1}{2}$ hours of life. At $1 \frac{1}{2}$ hours of age the mean $\mathrm{O}_{2}$ consumption was $6.4 \mathrm{ml} / \mathrm{kg}$ per $\min \pm \mathbf{0} \cdot 15$ (mean $\pm \mathrm{SE}$ ). No significant relationship was found between the rate of $\mathrm{O}_{2}$ consumption per $\mathrm{kg}$ body weight and the baby's birthweight, rectal temperature, room temperature, or the method of management (Fig. 1). Analgesics given during

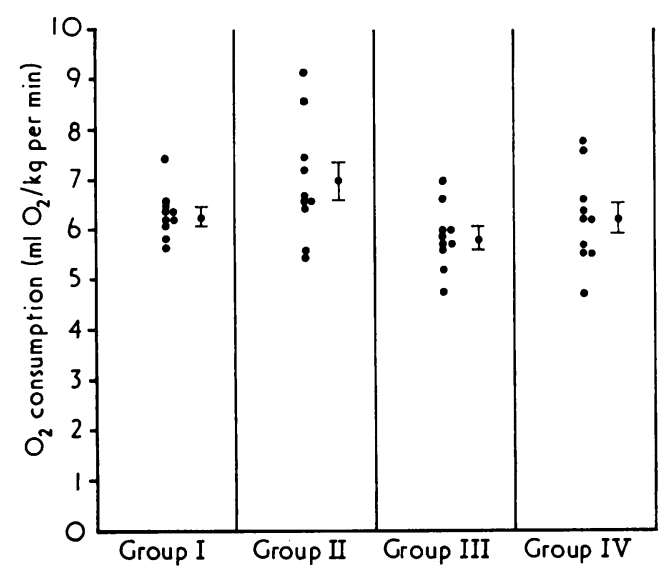

Fig. $1 \mathrm{O}_{2}$ consumption of babies aged $1 \frac{1}{2}$ hours according to the method of management (mean $\pm S E$ ).

labour did not influence the baby's rate of $\mathrm{O}_{2}$ consumption at this time. In contrast, rectal temperature at $1 \frac{1}{2}$ hours was largely dependent upon the method of management (Fig. 2). Babies in group 1 who had received primary toilet without a radiant heater had the lowest mean rectal temperature of $35.8{ }^{\circ} \mathrm{C} \pm \mathbf{0} \cdot 28$ (mean $\pm \mathrm{SE}$ ). In group 2 no primary toilet had been carried out resulting in a higher mean rectal temperature of $35.0{ }^{\circ} \mathrm{C} \pm 0 \cdot 36$, although this increase was not significant. Babies in

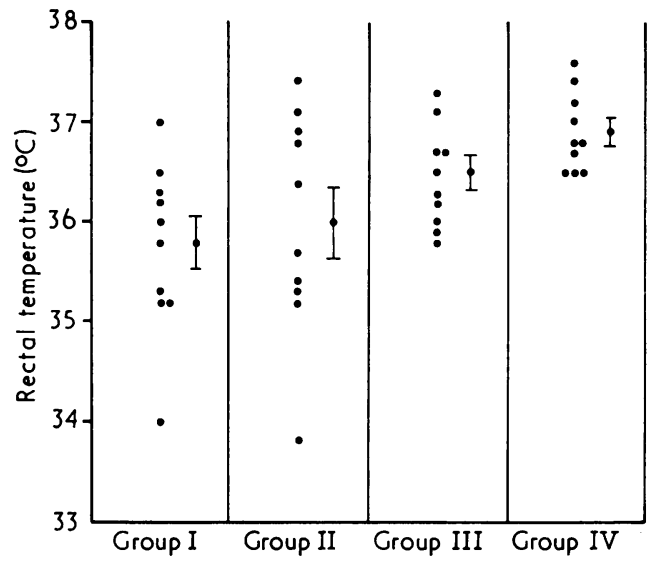

Fig. 2 Rectal temperature of babies aged $1 \frac{1}{2}$ hours according to the method of management (mean $\pm S E$ ).

group 3 who had received primary toilet and had been warmed with a radiant heater, had a mean rectal temperature of $36 \cdot 5{ }^{\circ} \mathrm{C} \pm 0 \cdot 18$, significantly higher than in groups 1 and $2(P<0 \cdot 05$, Students' $t$ test). The highest mean rectal temperature of 36.9 ${ }^{\circ} \mathrm{C} \pm 0.12$ was found in group 4 ; these babies were not washed and were warmed with a radiant heater, and their temperature was higher than in group 3 $(P<0.05)$.

Birthweight ranged from 2.38 to $3.97 \mathrm{~kg}$ (mean $3.26 \mathrm{~kg} \pm 0.06)$ and was related to body temperature $(\mathrm{P}<0 \cdot 01)$. There was no significant difference in the mean birthweight of each group.

Room temperature varied between $21.5{ }^{\circ} \mathrm{C}$ and $27 \cdot 1{ }^{\circ} \mathrm{C}$ but was not found to influence the baby's rectal temperature. However, a radiant heater was found to increase the mean room temperature from 23.7 to $24 \cdot 6^{\circ} \mathrm{C}$ after $1 \frac{1}{2}$ hours $(P<0 \cdot 05)$. Despite this, there was no significant difference in the mean room temperature of the four groups of babies studied.

Standardised cool exposure. The rate of $\mathrm{O}_{2}$ consumption measured in 32 normal babies after 20 minutes in a cool incubator is shown related to the age of the baby in hours in Fig. 3. Since a preliminary measurement of $\mathrm{O}_{2}$ consumption was not made under thermoneutral conditions, the response to cooling is illustrated using a mean minimum value derived from other babies of similar birthweight aged 4-24 hours. A small but highly significant increase in $\mathrm{O}_{2}$ consumption occurred during the first 24 hours of life $(\mathrm{P}<0 \cdot 001)$. The rate of $\mathrm{O}_{2}$ consumption after cooling was not related to the timing or amount of maternal analgesia, or to the baby's birthweight or rectal temperature. Birthweight did not influence rectal temperature after this period of cooling. 


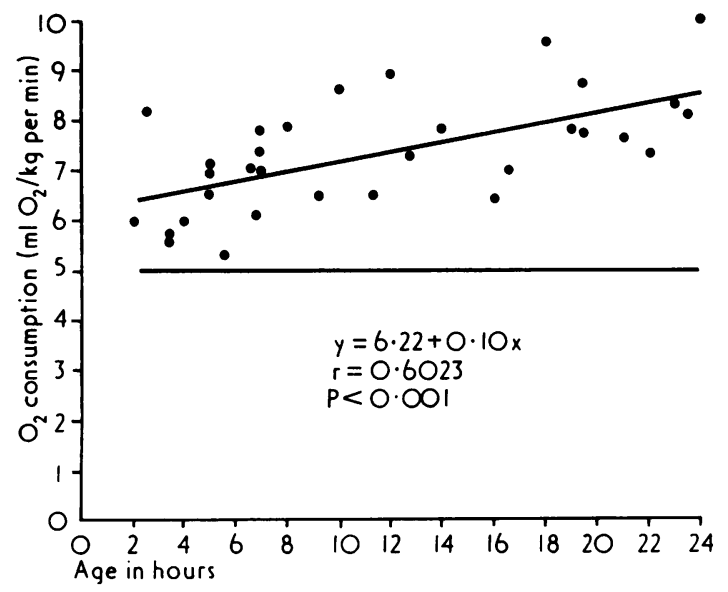

Fig. $3 \mathrm{O}_{2}$ consumption after 20 minutes in a cool environment according to the baby's age in hours. The lower line represents mean minimum $\mathrm{O}_{2}$ consumption derived from other babies of similar birthweight aged 4-24 hours in a thermoneutral environment.

\section{Discussion}

It has already been established that the rapid fall in body temperature occurring after birth can be prevented by drying the baby thoroughly and placing it in an incubator at a thermoneutral temperature. If resuscitation is required, a radiant heater above the naked baby will minimise heat loss during the first 30 minutes of life (Du and Oliver, 1969). This study has shown that a radiant heater can effectively maintain body temperature for an hour and a half while the baby is in the cool environment of the delivery room. Since the unit is not servo controlled, there may be some possibility of overheating and rectal temperature should be checked regularly when the heater is in use for longer than $1 \frac{1}{2}$ hours above a well wrapped term baby.

The 'primary toilet' procedure resulted in colder babies, and the drop in temperature was most marked in those under radiant heaters. Washing a baby soon after birth clearly contributes to a fall in body temperature and for this reason it is difficult to justify this practice. The relationship between birthweight and body temperature indicates that low birthweight babies are particularly at risk.

The low rate of $\mathrm{O}_{2}$ consumption recorded at $1 \frac{1}{2}$ hours was a surprising finding when such a high proportion of babies had a low rectal temperature. The mean $\mathrm{O}_{2}$ consumption of $6.4 \mathrm{ml} / \mathrm{kg}$ per min was only $20 \%$ greater than the minimum rate recorded by others during the first 12 hours of life
(Brück, 1961 ; Hey, 1971). In a similar group of babies, Brück showed an increase in heat production of $37 \%$ after 60 minutes at $28{ }^{\circ} \mathrm{C}$ and $108 \%$ after 60 minutes at $23{ }^{\circ} \mathrm{C}$. A fall in metabolic rate with body temperature (the Q10 effect) was not observed and it is unlikely that this phenomenon is relevant in babies of normal birthweight with body temperatures above $35^{\circ} \mathrm{C}$. In the present study no relationship was found between body temperature and $\mathrm{O}_{2}$ consumption. One explanation for the variation in response to cooling may be an effect noted by Brück (1961) and by Mestyán et al. (1962). In cold babies placed in a heat-gaining environment, heat production quickly decreases to minimum, despite a low rectal temperature. Subsequent studies have confirmed that $\mathrm{O}_{2}$ consumption is predominantly a function of the temperature gradient between body surface and the environment, rather than the absolute values of either deep body or surface temperature (Adamsons et al., 1965).

The standardised period of cool exposure was designed to test this, but $\mathrm{O}_{2}$ consumption in this heat-losing environment was no greater during the first few hours of life than in those babies warmly swaddled. However, over the whole 24-hour period there was a highly significant increase in $\mathrm{O}_{2}$ consumption with age. The poor response at $1 \frac{1}{2}$ hours is therefore not due to warming of the body surface but represents real limitation in the baby's response to cooling soon after birth. The response improved slowly during the first 24 hours and continues to increase over the first few days of life (Hey and Katz, 1969).

It may be possible to show a larger metabolic response to cold soon after birth if the baby is exposed to a lower environmental temperature for a longer period. Brück (1961), using an environmental temperature of $23{ }^{\circ} \mathrm{C}$ for 60 minutes, observed the maximum increase in heat production at 50 minutes after a fall in rectal temperature. Adamsons et al. (1965) recorded an $\mathrm{O}_{2}$ consumption of $15 \cdot 2 \mathrm{ml} / \mathrm{kg}$ per minute in a $3.8 \mathrm{~kg}$ baby at $15^{\circ} \mathrm{C}$ at $2 \frac{1}{2}$ hours of age and concluded that the poor thermal stability of newborn babies cannot be ascribed to impaired heat production. However, it appears that not only is there considerable variation in the response in the first few hours, but that the degree and duration of cooling required to produce an increase in heat production is greater than at any other time.

The increase in response observed in this study over the first hours indicates an increasing capability to compensate for situations of increased heat loss. Radiant heaters can provide valuable support for babies in the cool conditions of the delivery room, but unless environmental temperature is high, the first wash should be delayed. 
We thank Miss Travis and the Maternity Unit staff for co-operation, and Professor D. Hull for advice.

\section{References}

Adamsons, K., Gandy, G. M., and James, L. S. (1965). The influence of thermal factors upon oxygen consumption of the newborn human infant. Journal of Pediatrics, 66, 495-508.

Brück, K. (1961). Temperature regulation in the newborn infant. Biologia Neonatorum, 3, 65-119.

Du, J. N. H., and Oliver, T. K. (1969). The baby in the delivery room. Journal of the American Medical Association, 207, 1502-1504.

Hey, E. N. (1971). Recent Advances in Paediatrics, 4th ed., p. 171. Ed. by D. Gairdner and D. Hull. Churchill, London.

Hey, E. N., and Katz, G. (1969). Temporary loss of a metabolic response to cold stress in infants of low birthweight. Archives of Disease in Childhood, 44, 323-330.

Hey, E. N., and Mount, L. E. (1967). Heat losses from babies in incubators. Archives of Disease in Childhood, 42, 75-84.

Mestyán, G., Varga, F., Fohl, E., and Heim, T. (1962). Oxygen consumption of hyper- and hypothermic premature infants. Archives of Disease in Childhood, 37, 466469.

Scopes, J. W., and Ahmed, I. (1966). Indirect assessment of oxygen requirements in newborn babies by monitoring deep body temperature. Archives of Disease in Childhood, 41, 25-33.

Smales, O. R. C. (1978). Simple method for measuring oxygen consumption in babies. Archives of Disease in Childhood, 53, 53-57.

Stupfel, M. (1959). Action du Gaz Carbonique sur la Thermorégulation. Étude Experimentale Chez le Rat Blanc. Jouve, Paris.

Correspondence to Dr O. R. C. Smales, Department of Child Health, University Hospital and Medical School, Clifton Blvd., Nottingham. 